\title{
Development of an Effective Propagation Protocol for Osbeckia octandra (L.) DC. (Heen Bovitiya)
}

\author{
Postgraduate Institute of Agriculture \\ University of Peradeniya \\ Sri Lanka
}

D.M.I.C.B. Dassanayake*, S.A. Krishnarajah ${ }^{1}$ and J.P. Eeswara ${ }^{2}$

\begin{abstract}
Effective multiplication technique for mass propagation of Osbeckia octandra (L.) DC, an endemic species to Sri Lanka with potential values as an ornamental flowering plant was investigated. Production of planting materials was evaluated using seeds, conventional vegetative propagation and tissue culture techniques. Effect of substrate on in-vivo seed germination and effect of Gibberellic acid $\left(G A_{3}\right)$ on seed germination under in-vivo and in-vitro conditions were investigated. Survival rates of in-vitro germinated seedlings were tested with three different acclimatization environments. Rooting performances of cuttings were evaluated by using both softwood and semi-hardwood cuttings treated with Indole-3-butyric acid (IBA). Effect of shoot multiplication of plant under in-vitro conditions was investigated by establishing nodal cultures. The substrate containing sand: soil at 1:1 ratio was found as the best for seed germination. There was no effect of $\mathrm{GA}_{3}$ on seed germination and a higher $(P<0.05)$ number of seedlings $(61.27 \%)$ could be obtained by the seeds under in-vitro conditions. Use of non-sterilized growing medium (sand: soil - 1:1) in a polythene sleeve arranged as a single propagator was the most cost effective way of acclimatizing in-vitro grown plants, and use of semi-hardwood cuttings with an initial dip in $500 \mathrm{mg} \mathrm{L}^{-1}$ IBA solution for 10 minutes was the most effective method for rapid plant multiplication. A successful shoot production was achieved by culturing single nodes on full strength Murashige and Skoog medium supplemented with $0.1 \mathrm{mg} \mathrm{L}^{-1}$ Benzyl-aminopurine under in-vitro conditions.
\end{abstract}

Keywords: Osbeckia octandra, micropropagation, seeds, stem cuttings

\section{INTRODUCTION}

Osbeckia octandra (L) DC. (Heen-bovitiya) is a branched shrub, endemic to Sri Lanka and commonly distributed in Dry, Wet and Montane zone within the country (Dassanayake and Fosberg, 1987). It is one of the wild plants, identified by the Royal Botanic Gardens, Peradeniya to introduce as a flowering ornamental to the floriculture industry in Sri Lanka, because of its contrasting flower color opposed to its foliage, free flowering nature, simple cultivation methods and good adaptability in growing under greenhouse conditions (Krishnarajah et al., 2002). However, the potential of $O$. octandra to be improved as a flowering ornamental has not yet been fully exploited.

\footnotetext{
1 Floriculture Research and Development Unit, Royal Botanic Gardens, Peradeniya, Sri Lanka

2 Department of Crop Science, Faculty of Agriculture, University of Peradeniya, Sri Lanka

* Corresponding author: d.chanima@yahoo.com
} 
In nature, $O$. octandra is regenerated mainly through seeds and rarely by producing roots when shoot tips grow towards soil (personal observations). $O$. octandra seeds are very small and have very low germination rate. Furthermore, there is no published information on germination behavior of seeds under both natural and controlled environment. The plant can successfully be propagated by softwood cuttings with an initial dip in IBA powder (Katulanda, 1997), and also by using 4-5 inch stem cuttings, planted in a sand medium without growth regulators (Dhanasekara et al.,1998). However, propagation of $O$. octandra through stem cuttings can only be used in small scale production as it limits the number of cuttings required at initial stage of a commercial production. Therefore, it is vital to develop a mass propagation protocol to generate the required amounts of planting materials for commercial introduction of this plant as a potted ornamental.

Micropropagation protocols for $O$. octandra was developed by using $1-1.5 \mathrm{~cm}$ nodal segments on $1 / 2$ strength MS (Murashige and Skoog, 1962) medium supplemented with 0.1 $\mathrm{mgL}^{-1}$ BAP (Dhanasekara et al., 1998). As a mass propagation method, production of plantlets through micropropagation is time consuming and expensive compared to conventional vegetative propagation. Therefore, it is advantageous to identify an effective propagation method to multiply plants before introducing them to the commercial production. Thus, present study was conducted with the objective of developing an effective propagation protocol for $O$. octandra with the aim of introducing plant to floriculture industry as a potted flowering ornamental.

\section{MATERIALS AND METHODS}

The experiments were carried out in the tissue culture laboratory and in a plant house at Department of Crop Science, Faculty of Agriculture, University of Peradeniya, Sri Lanka. The experiments were arranged in a Complete Randomized Design (CRD), having three replications for each treatment.

\section{Plant materials}

Three types of plant materials including dried seed pods, immature green colour seed pods and shoots were collected from mother plant stock maintained at the Royal Botanic Gardens, Sri Lanka.

\section{Evaluating potting mixtures}

Effect of different potting mixtures on germination and growth of seeds was investigated under in vivo conditions. Extracted seeds from dried seed pods were treated with $500 \mathrm{mgL}^{-1}$ $\mathrm{GA}_{3}$ solution for 30 minutes and sown on three different potting mixtures of sand only, sand : soil in 1:1 and sand : soil : coir dust in 1:1:1 as 200 seeds per $7 \mathrm{~cm}$ diameter, plastic container. River sand and red, yellow podzolic soil were used as components throughout the preparation of above potting mixtures. The number of seeds germinated in each potting mixture was counted in weekly intervals.

\section{In vivo and in vitro germination of seeds}

Effect of gibberellic acid $\left(\mathrm{GA}_{3}\right)$ on seed germination under in vivo and in vitro $\left(25^{\circ} \mathrm{C}\right.$ at $16-\mathrm{h}$ light/8-h dark regime under cool white fluorescent light with 1000-1300 Lux intensity) conditions was evaluated. Seeds were extracted from dried seed pods and dipped either in 
distilled water or $500 \mathrm{mg} \mathrm{L}^{-1} \mathrm{GA}_{3}$ solution for 30 minutes before sowing on a medium consisted of sand and soil in 1:1 mixture under in vivo conditions.

For in vitro germination, the immature green colour seed pods (about 10-15 days after fertilization) were surface sterilized with $10 \%$ (v/v) commercially availabale bleach $(\mathrm{NaOCl})$ for 10 minutes followed by $70 \%(\mathrm{v} / \mathrm{v})$ ethanol and seeds were extracted under aseptic conditions. Extracted seeds were then dipped either in distilled water or in $500 \mathrm{mg} \mathrm{L}^{-1} \mathrm{GA}_{3}$ solution (filter sterilized using $0.45 \mu \mathrm{m}$ sterile memberane filters) for 30 minutes before establishing on $1 / 4$ strength MS medium with $3 \%$ sucrose, supplemented with or without 0.1 $\mathrm{mg} \mathrm{L}^{-1} \mathrm{GA}_{3}$. Each treatment consisted of 200 seeds per container or culture vessel and the number of seeds germinated was counted in weekly intervals.

\section{Acclimatization of in vitro germinated seedlings}

The seedlings obtained from the in vitro seed cultures were transferred to $1 / 4$ strength MS medium without growth regulators and were allowed to grow further until the seedlings get ready for the acclimatization. Once the seedlings achieved about $8-10 \mathrm{~cm}$ in height, they were taken out from the culture vessels and were introduced to the glass bottles filled either with sterilized or non-sterilized growing medium containing sand and soil in 1:1 mixture and about $40 \mathrm{~cm}$ length transparent polythene sleeves, filled with the above medium without sterilization. Both glass bottles and polythene sleeves (containing four seedlings per each) with growing media were arranged as single propagators and the seedlings inside the propagators were gradually exposed to the in vivo conditions as the seedlings adapt. The number of seedlings successfully survived was recorded at the end of the $4^{\text {th }}$ week of acclimatization procedure.

\section{Propagation of plants by stem cuttings}

The effects of different levels of Indole-3-butyric acid (IBA) on rooting and establishment of the two different types of stem cuttings (softwood and semi-hardwood), in pure sand medium was investigated by introducing them into single propagators as described by Krishnarajah et al., 2002. Uniform sized, 10-12 cm length, healthy stem cuttings of both softwood and semi-hardwood types were obtained from the collected shoots and the cuttings were treated with an initial dip in four different concentrations $(0,500,1000$ and $2000 \mathrm{mgL}^{-1}$ ) of IBA for 10 minutes before the establishment. Survival rate of the cuttings was recorded in two weeks intervals. Number of roots and total root lengths per cutting were counted and measured subsequently at the end of third week of establishment.

\section{In vitro multiplication of nodal segments}

The effects of $1 / 2$ and full strength MS media combined with different levels of Benzylaminopurine (BAP) on axillary shoots formation of the stem nodes were investigated. Nodal segments $(1-1.5 \mathrm{~cm})$ with unopen shoots were surface setrilized with $10 \%(\mathrm{v} / \mathrm{v})$ commercially available bleach $(\mathrm{NaOCl})$ for 10 minutes and were then established either in $1 / 2$ or full strength MS media supplemented with four concentrations of $\left(0,0.1,1\right.$ and $\left.2 \mathrm{mg} \mathrm{L}^{-1}\right)$ BAP under aseptic conditions. Shoot production per node was counted in weekly intervals. The appearance of the shoots produced were evaluated using a scale as ' 0 - shoots not growing', '1 - abnormal', ' 2 - fair' and ' 3 - good' and the number of culture vesseles with shoots relevant to these scale were recorded at the end of the $4^{\text {th }}$ week of culture establishment. Multiplied shoots were transferred to full strength MS medium without any 
growth regulators and plantlets produced were acclimatized using the method developed for in vitro germinated $O$. octandra seedlings.

\section{Statistical analyses}

The parametric data (root length), were statistically analyzed by Analysis of Variance (ANOVA) and Duncan's multiple range test (DMRT) was used to compare the means while the non-parametric data (numer of seedlings survived, number of roots, number of cuttings survived, number of shoots and performance of shoots) were analyzed by categorical data analysis (Chi-square test and Kruskall wallis test) using Statistical Analysis Software (SAS, 2009).

\section{RESULTS AND DISCUSSION}

\section{Evaluating potting mixtures}

The mean seed germination percentage on sand only $(39.83 \%)$ and sand : soil in 1:1 $(41.84 \%)$ potting mixtures were significantly higher $(P<0.05)$ than that of the seeds on the substrate containing sand : soil : coir dust in 1:1:1 (18.67\%) mixture, after five weeks of seeds sowing (Table 1$)$. The highest germination percentage $(41.84 \%)$ was observed in the medium containing sand and soil in 1:1 mixture while the lowest was on the medium consisted of coir dust as a substance, indicating that coir dust has toxic effect on seed germination where the excess salinity and phenolic compounds on coir can be a problem as described by Ma and Nichols, 2004. In addition, the percentage of seed germination in coir dust incorporated mixture was dropped at the end of the $5^{\text {th }}$ week as the poor growth performances of seedlings emerged on the medium.

Table 1. Germination percentage of seeds (Mean) on different potting mixtures under in vivo conditions

\begin{tabular}{lccccc}
\hline \multirow{2}{*}{ Potting mixture } & \multicolumn{5}{c}{ Germination of seeds (\%) } \\
\cline { 2 - 6 } & Week 1 & Week 2 & Week 3 & Week 4 & Week 5 $^{\text {Sand only }}$ \\
\cline { 2 - 6 } & $6.00^{\mathrm{a}}$ & $12.50^{\mathrm{a}}$ & $28.84^{\mathrm{a}}$ & $37.50^{\mathrm{a}}$ & $39.83^{\mathrm{a}}$ \\
\hline Sand : Soil & $7.34^{\mathrm{a}}$ & $15.17^{\mathrm{a}}$ & $31.50^{\mathrm{a}}$ & $39.34^{\mathrm{a}}$ & $41.84^{\mathrm{a}}$ \\
\hline Sand : Soil : Coir dust & $5.34^{\mathrm{a}}$ & $9.17^{\mathrm{b}}$ & $20.34^{\mathrm{b}}$ & $25.50^{\mathrm{b}}$ & $18.67^{\mathrm{b}}$ \\
\hline $\begin{array}{l}\text { Germination data is based on } \\
\text { significantly different }(P<0.05) .\end{array}$ & replicates of 200 seeds. Means with different superscripts in columns are \\
\end{tabular}

\section{In vivo and in vitro germination of seeds}

The results (Table 2) showed that gibberellins has no effect $(P<0.05)$ on seed germination under both in vivo and in vitro conditions indicating that there is no seed dormancy where the primary event of breaking seed dormancy is stimulated by gibberellins (Harms and Oplinger, 1988). 
Table 2. Germination percentage of seeds (Mean) treated with or without $\mathrm{GA}_{3}$ under in vivo and in vitro conditions

\begin{tabular}{llllll}
\hline \multirow{2}{*}{ GA $_{3}$ application } & \multicolumn{5}{c}{ Germination percentage of seeds (\%) } \\
\cline { 2 - 6 } & Week 1 & Week 2 & Week 3 & Week 4 & Week 5 \\
\hline $\begin{array}{l}\text { In vivo } \\
\text { No } \mathrm{GA}_{3} \text { application }\end{array}$ & $6.00^{\mathrm{b}}$ & $14.50^{\mathrm{b}}$ & $27.00^{\mathrm{b}}$ & $40.84^{\mathrm{b}}$ & $42.84^{\mathrm{b}}$ \\
\hline Seed dip $\left(500 \mathrm{mg} \mathrm{L}^{-1} \mathrm{GA}_{3}\right)$ & $5.16^{\mathrm{b}}$ & $13.16^{\mathrm{b}}$ & $25.66^{\mathrm{b}}$ & $39.16^{\mathrm{b}}$ & $41.66^{\mathrm{b}}$ \\
\hline In vitro & & & & & \\
\hline No $\mathrm{GA}_{3}$ application & $8.67^{\mathrm{a}}$ & $23.17^{\mathrm{a}}$ & $41.17^{\mathrm{a}}$ & $57.67^{\mathrm{a}}$ & $63.50^{\mathrm{a}}$ \\
\hline $\begin{array}{l}\text { Seed dip } \\
\left(500 \mathrm{mg} \mathrm{L}^{-1} \mathrm{GA}_{3}\right)\end{array}$ & $7.00^{\mathrm{a}}$ & $21.50^{\mathrm{a}}$ & $36.84^{\mathrm{a}}$ & $55.84^{\mathrm{a}}$ & $61.17^{\mathrm{a}}$ \\
\hline $\begin{array}{l}\text { Media supplement } \\
\left(0.1 \mathrm{mg} \mathrm{L}^{-1} \mathrm{GA}_{3}\right)\end{array}$ & $6.34^{\mathrm{ab}}$ & $20.84^{\mathrm{a}}$ & $36.00^{\mathrm{a}}$ & $53.50^{\mathrm{a}}$ & $60.16^{\mathrm{a}}$ \\
\hline $\begin{array}{l}\text { Germination data is based on 3 replicates of 200 seeds. Means with different superscripts in columns are } \\
\text { significantly different }(P<0.05) .\end{array}$ & & & &
\end{tabular}

The percentage germination (above $60 \%$ ) of seeds under in vitro conditions was significantly higher $(P<0.05)$ compared to the seeds germinated under in vivo conditions, implying that low germination observed under in vivo conditions is due to lack of storage material, which could be over come by growing seeds on an artificial medium ( $1 / 4$ strength MS medium with $3 \%$ sucrose). Even though, O. octandra produces large number of smaller seeds, no seedling population could be observed under the mother plants after seed dispersion. As the seeds produced are very small in size, it may be possible that the seeds do not contain enough storage materials to survive under natural conditions.

\section{Acclimatization of in vitro germinated seedlings}

There was no significant difference $(P<0.05)$ among the number of plants survived, when in vitro germinated seedlings were acclimatized by using either a sterilized or a non-sterilized growing medium inside a glass bottle or a non-sterilized growing medium in a transparent polythene sleeve (Table 3). As the results reveals, in vitro germinated seedlings could successfully be acclimatized using all three methods and nearly all the acclimatized plants survived (93\%). Out of these three methods, use of a polythene sleeve as a single propagator with a mixture of sand and soil without sterilization will be the most cost effective method for acclimatizing in vitro germinated $O$. octandra seedlings. 
Table 3. Number of seedlings survived $(\mathrm{Mean} \pm \mathrm{SE})$ in different acclimatization environments

\begin{tabular}{lc}
\hline Acclimatization environment & Number of seedlings survived \\
\hline Sterilized media in glass bottle & $14.67 \pm 0.33$ \\
Non-sterilized media in glass bottle & $14.67 \pm 0.33$ \\
Non-sterilized media in polythene sleeve & $15.00 \pm 0.58$ \\
\hline Survival data is based on 4 replicates of 4 seedlings. &
\end{tabular}

\section{Propagation of plants by stem cuttings}

Number of both softwood and semi-hardwood cuttings survived, decreased with the time, as the concentration of IBA increases (Figure 1). Furthermore, survival of softwood cuttings decreased rapidly compared to semi-hardwood cuttings in all the IBA concentrations.

\section{(i) Survival rate of the cuttings}

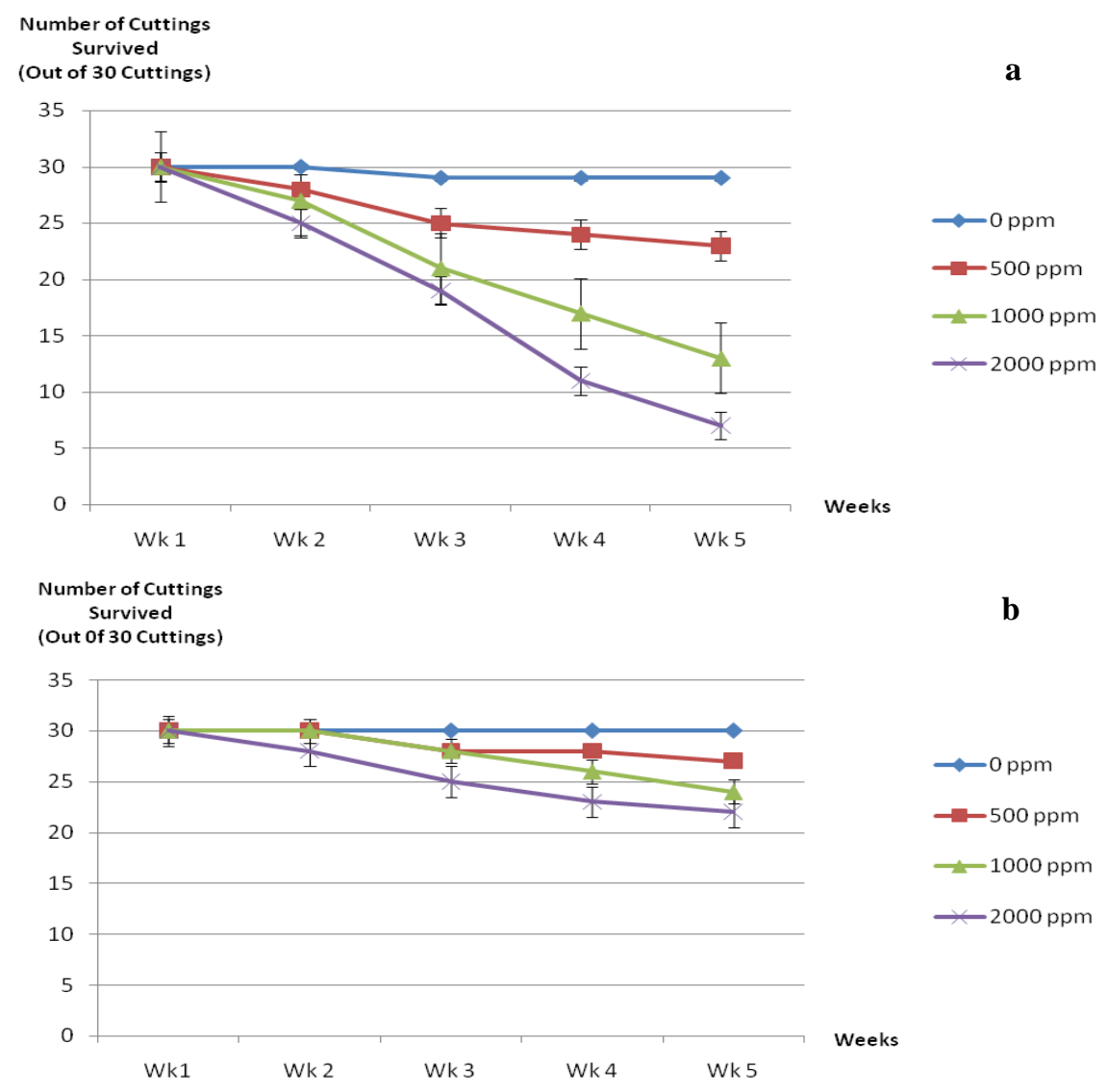

Figure 1. Number of softwood (a) and semi-hardwood (b) cuttings survived after applying different concentrations of IBA.

Data shown are the means of three replicates. Vertical bars represent \pm standard error (SE) 
In corporation with the other hormones, auxins stimulate fundamental processes such as cell elongation and division (Kende and Zeevaart, 1997). However, when plants are treated with auxins it caused to increase plant internal level of auxins. Increase in auxin concentrations at the cellular sites of actions, induces variety of growth abnormalities including epinasty and inhibition of shoot (decreased internode elongation and leaf area) and root growth (Sterling and Hall, 1997; Grossman, 1998). In addition, stimulation of ethylene biosynthesis is a common response when auxins are applied to sensitive species (Klee and Lanahan, 1995). Thus, it may be possible that application of IBA at higher concentrations may lead production of ethylene in $O$. octandra plants causing toxic effects.

\section{(ii) Number of roots and total root length}

Mean number of roots produced per cutting in both softwood and semi-hardwood types increased as the IBA concentration increased (Table 4). In softwood type, the number of roots produced per cutting was significantly lower $(P<0.05)$ than that of the roots produced per cutting in semi-hardwood type (Plate 1, Table 4$)$.

Furthermore, mean total root length in semi-hardwood type cuttings became lower as the concentration of IBA increased, while softwood type cuttings has increased their mean total root length at a declining rate. Significantly higher $(P<0.05)$ total root lengths were observed in semi-hardwood cuttings compared to the softwood cuttings in all the IBA treatments, probably due to the production of lower number of roots per cutting as indicated in Table 4.

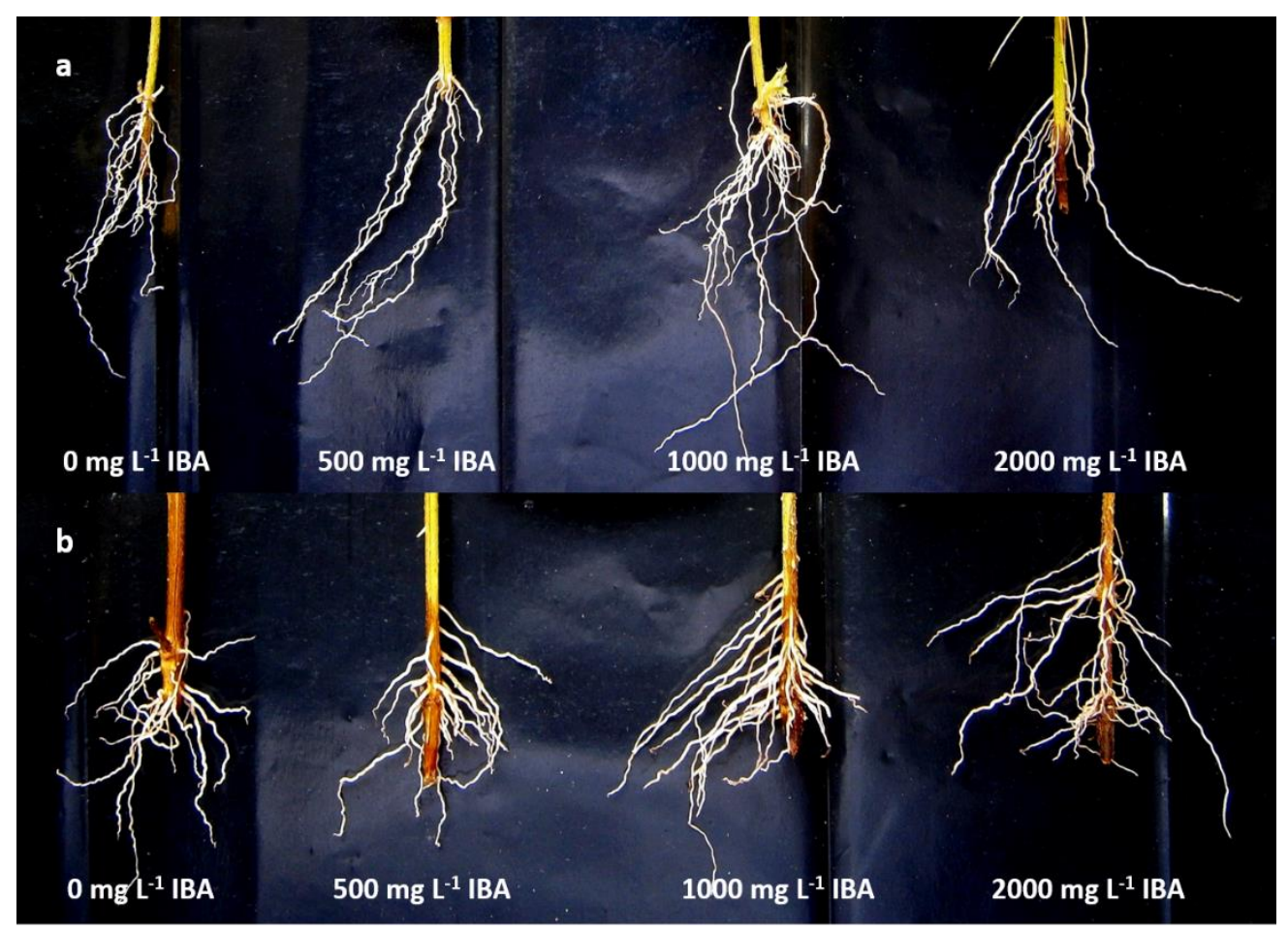

Plate 1. Effect of four different concentrations of IBA on rooting of two types of stem cuttings: (a) Softwood cuttings (b) Semi-hardwood cuttings 
Table 4. Number of roots produced per cutting (Mean \pm SE) treated with IBA and their total root lengths at the end of $3^{\text {rd }}$ week after establishment

\begin{tabular}{lccc}
\hline Type of cutting & IBA concentration & $\begin{array}{c}\text { Number of } \\
\text { roots/cutting }\end{array}$ & $\begin{array}{c}\text { Total root length } \\
(\mathbf{c m})\end{array}$ \\
\hline \multirow{2}{*}{ Softwood } & $0 \mathrm{mg} \mathrm{L}^{-1}$ & $11.00^{\mathrm{d}} \pm 0.57$ & $10.11^{\mathrm{d}} \pm 0.39$ \\
\cline { 2 - 4 } & $500 \mathrm{mg} \mathrm{L}^{-1}$ & $15.33^{\mathrm{c}} \pm 0.33$ & $13.37^{\mathrm{c}} \pm 0.46$ \\
\cline { 2 - 4 } & $1000 \mathrm{mg} \mathrm{L}^{-1}$ & $18.00^{\mathrm{b}} \pm 0.58$ & $14.35^{\mathrm{c}} \pm 0.22$ \\
\hline \multirow{2}{*}{ Semi-hardwood } & $2000 \mathrm{mg} \mathrm{L}^{-1}$ & $18.00^{\mathrm{b}} \pm 0.58$ & $14.27^{\mathrm{c}} \pm 0.17$ \\
\cline { 2 - 4 } & $0 \mathrm{mg} \mathrm{L}^{-1}$ & $16.33^{\mathrm{bc}} \pm 0.33$ & $20.17^{\mathrm{a}} \pm 0.62$ \\
\cline { 2 - 4 } & $500 \mathrm{mg} \mathrm{L}^{-1}$ & $19.33^{\mathrm{b}} \pm 0.33$ & $20.90^{\mathrm{a}} \pm 0.49$ \\
\cline { 2 - 4 } & $1000 \mathrm{mg} \mathrm{L}^{-1}$ & $23.67^{\mathrm{a}} \pm 0.33$ & $17.35^{\mathrm{b}} \pm 0.11$ \\
\hline 2000 mg L & $24.67^{\mathrm{a}} \pm 0.33$ & $17.31^{\mathrm{b}} \pm 0.11$ \\
\hline
\end{tabular}

Rooting data is based
different $(P<0.05)$.

However, the semi-hardwood cuttings treated with $0 \mathrm{mg} \mathrm{L}^{-1}$ or $500 \mathrm{mg} \mathrm{L}^{-1}$ IBA solutions showed the highest $(P<0.05)$ significant total root length among the same type of cuttings in other IBA treatments. It is well known fact that application of auxins increases root initiation while inhibits root elongation (Wiesman and Lavee, 1995). Thus, it may be possible that lower concentrations of IBA produced higher number of lengthy roots while higher number of shorter roots is produced at higher concentrations of IBA. Therefore, the total root length of the both type of cuttings in $1000 \mathrm{mgL}^{-1}$ and $2000 \mathrm{mgL}^{-1}$ IBA treatments were significantly lower than that of the cuttings in other IBA treatments.

\section{In vitro multiplication of nodal segments}

Nodal segments of $O$. octandra introduced to the tissue culture medium supplemented with BAP showed an active growth of axillary buds. Buds grew elongated and rooted easily in the medium. Multiplication of shoots was also achieved within a short period of time (within 4 weeks) in agreement with the results of Dhanasekara et al., 1998.

As the BAP concentration increases, the number of shoots produced by the nodal segments cultured in both media ( $1 / 2$ strength and full strength MS) were started to increase. At the end of the $4^{\text {th }}$ week of culture establishment, the newly emerged shoots in both media with $1 \mathrm{mg}$ $\mathrm{L}^{-1}$ and $2 \mathrm{mg} \mathrm{L}^{-1}$ BAP concentrations were appeared vitrified and could not be used for further growth. The number of shoots produced by the nodal segments in medium supplemented with $0.1 \mathrm{mg} \mathrm{L}^{-1}$ BAP was significantly higher $(P<0.05)$ than that of the shoots produced by the medium without any BAP supplement (Table 5). 
Table 5. Number of shoots produced per node (Mean \pm SE) on different media supplemented with different concentrations of BAP at the end of $4^{\text {th }}$ week after culture establishment

\begin{tabular}{ccc}
\hline Media Composition & BAP Concentration & Number of shoots/node \\
\hline \multirow{2}{*}{$1 / 2 \mathrm{MS}$} & $0 \mathrm{mgL}^{-1}$ & $1.89^{\mathrm{b}} \pm 0.11$ \\
\cline { 2 - 3 } & $0.1 \mathrm{mgL}^{-1}$ & $3.67^{\mathrm{a}} \pm 0.19$ \\
\cline { 2 - 3 } & $1 \mathrm{mgL}^{-1}$ & Shoots vitrified \\
\hline \multirow{2}{*}{ Full MS } & $0 \mathrm{mgL}^{-1}$ & Shoots vitrified \\
\cline { 2 - 3 } & $0.1 \mathrm{mgL}^{-1}$ & $2.11^{\mathrm{b}} \pm 0.11$ \\
\hline & $1 \mathrm{mgL}^{-1}$ & $4.22^{\mathrm{a}} \pm 0.22$ \\
\hline & $2 \mathrm{mgL}^{-1}$ & Shoots vitrified \\
\hline
\end{tabular}

Shoot production data is based on 3 replicates of 10 nodal segments. Means with different superscripts in columns are significantly different $(P<0.05)$.

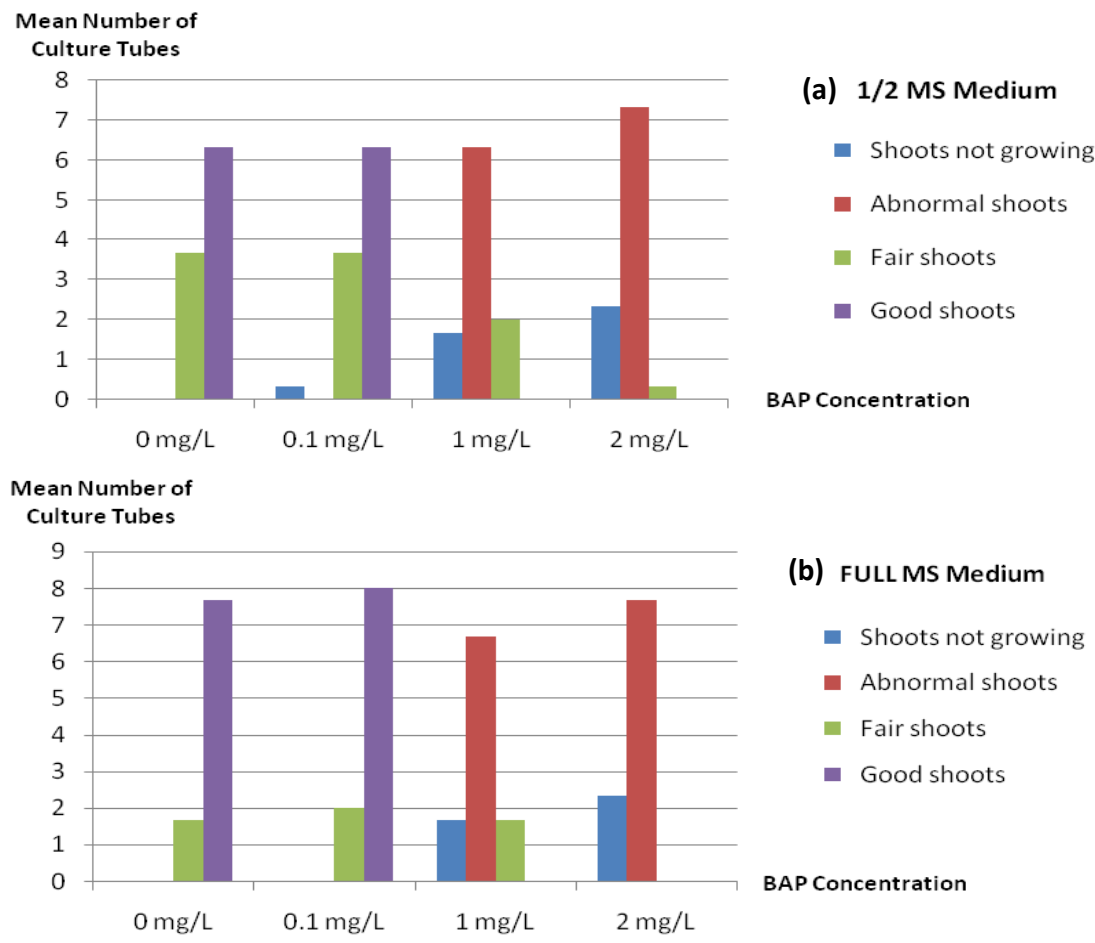

Figure 2. Number of 'shoots not growing', abnormal shoots', fair shoots' and 'good shoots' in response to different media compositions supplemented with BAP

Number of culture vessels including 'shoots not growing' and 'abnormal shoots' was very high in both medium with higher BAP concentrations and shoots appeared vitrified (Figure 
2). Higher concentrations of BAP (1 and $\left.2 \mathrm{mgL}^{-1}\right)$ in the medium initially increased multiplication, but eventually reduced the quality of the shoots. When the leaves of new shoots touched the medium, they thickened, enlarged and formed calli presumably due to the high concentration of BAP. Similar results were reported by Eeswara et al., in 1998 for in vitro propagated neem shoots. In addition, the visual appearance of the shoots produced on full strength MS medium was better than the shoots produced in $1 \frac{1}{2}$ MS medium (Plate 2).

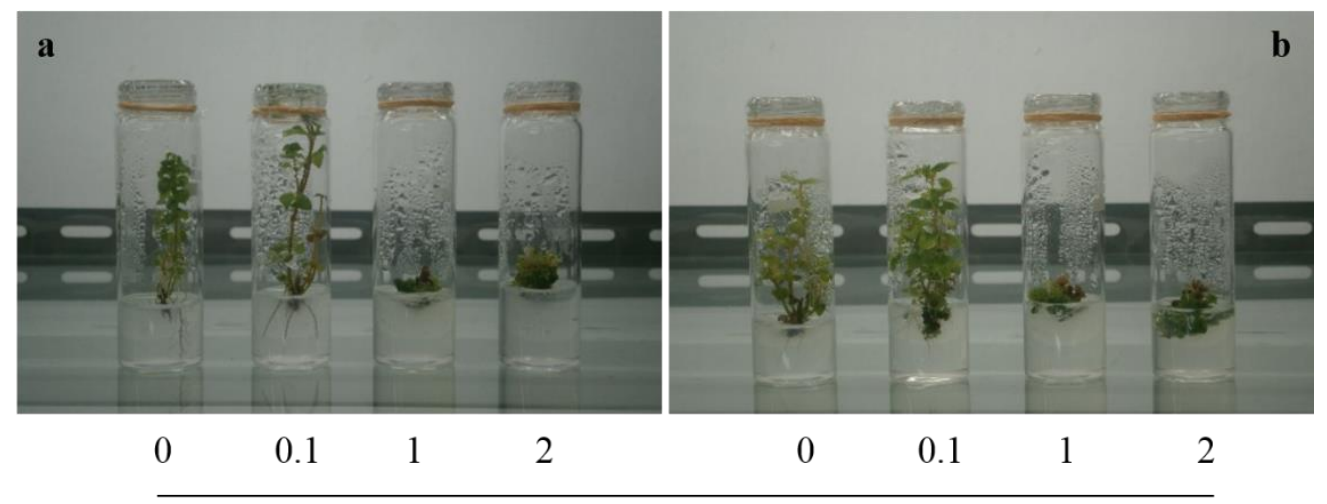

BAP Concentration $\left(\mathrm{mg} \mathrm{L}^{-1}\right)$

\section{Plate 2. Effect of media composition and BAP concentrations on shoot production of nodes under in vitro conditions: (a) $1 / 2$ strength MS medium (b) Full strength MS medium}

Rooting of micropropagated shoots was achieved fairly easily, using full strength MS medium without incorporating rooting hormones under in vitro conditions. The rooted shoots were then acclimatized by introducing them into a non-sterilized growing medium in polythene sleeves as described for in vitro germinated $O$. octandra seedlings.

\section{CONCLUSIONS}

Gibberelic acid $\left(\mathrm{GA}_{3}\right)$ has no effect on seed germination under in vivo (sand only or sand : soil in $1: 1$ mixture) and in vitro ( $1 / 4$ strength MS medium $+3 \%$ sucrose) conditions. Comparatively, higher number of seedlings can be obtained by in vitro propagation of seeds. At the stage of acclimatization, it is better to use non-sterilized growing medium in a transparent polythene sleeve as the acclimatization environment as it appears to be the most cost effective method.

A successful shoot production can be obtained by using nodes on full strength MS medium supplemented with $0.1 \mathrm{mg} \mathrm{L}^{-1}$ BAP under in vitro conditions. Even though nodal cultures produce fewer amounts of plantlets at a time, it is very clear that it consumes much less time compared to the in vitro seed cultures.

Conventional vegetative propagation is the most effective and reliable way of $O$. octandra plant production. The plant can easily and quickly (within 2-3 weeks) be propagated through rooting of semi-hardwood cuttings compared to mass propagation through tissue culture. The cuttings treated with $500 \mathrm{mgL}^{-1}$ concentration of IBA solution, in pure sand medium can be 
used for the purpose and a high level of humidity is needed to induce successful rooting of cuttings inside a propagator.

Even though micropropagation takes longer time to produce plants, an initial stock of plants could be produced through tissue culture, as this would reduce the number of plants being collected from the natural environment. These could then be used as starter material for conventional propagation by growers as well as for studies in value addition and flower induction.

\section{ACKNOWLEDGEMENTS}

Financial grant by the National Science Foundation (RG/2014/AG/03) is acknowledged.

\section{REFERENCES}

Dassanayake, M.D. and Fosberg, F.R. (1987). A Revised Handbook of Flora of Ceylon. 6,157-176. Amerind Publishing Co. Pvt. Ltd., New Delhi, India.

Dhanasekara, D.M.U.B., Krishnarajah, S.A. and Ratnayake, R.H.P.P.M. (1998). A comparison of different methods of vegetative propagation for Osbeckia octandra (L) DC. Proceeding of $55^{\text {th }}$ Annual Sessions Sri Lanka Association for the Advancement of Science. pp 64.

Eeswara, J.P., Stuchbury, S., Allan, E.J. and Mordue (Luntz), A.J. (1998). A standard procedure for the micropropagation of the neem tree (Azadirachta indica A Juss). Plant Cell Rep. 17 (3), 215-219

Grossman, K. (1998). Quinclorac belongs to a new class of highly selective auxin herbicides. Weed Sci. 46, 707-716.

Kende, H. and Zeevaart, J.A.D. (1997). The five "classical" plant hormones. Plant Cell. 9, 1197-1210.

Klee, H.J. and Lanahan, M.B. (1995). Transgenic plants in hormone biology. pp. 340-353. In: Davies P.J. (Ed). Plant Hormones: Physiology, Biochemistry and Molecular Biology. Springer, Dordrecht, Netherlands.

Krishnarajah, S.A. and Dhanasekara, D.M.U.B. (2002). Utilization of Wild Flora to Develop the Floriculture Industry. Annals of Sri Lanka Department of Agriculture, 4, 151-159

Katulanda, K.K.P. (1997). Introduction of novel ornamental plants to the floriculture industry. Final Year Research Project Report (unpublished data), Faculty of Agriculture, University of Peradeniya, Sri Lanka. pp. 1-6.

Ma, Y. and Nichols. D. (2004). Phytotoxicity and detoxification of fresh coir dust and coconut shell. Commun. Soil Sci. Plant Anal. 35, 205-218.

Murashige, T. and Skoog, F. (1962). A revised medium for rapid growth and bioassays with tobacco cultures. Physiol. Plant. 15, 473-497. 
SAS, (2009). SAS/STAT User's Guide. Version 6.12, SAS Institute Inc., Cary, North Carolina, USA.

Sterling, T.M. and Hall, J.C. (1997). Mechanism of action of natural auxins and the auxinic herbicides. pp. 111- 141. In: Roe, R.M., Burton, J.D. and Kuhr, R.J. (Ed). Herbicide activity: Toxicology, Biochemistry and Molecular Biology. IOS Press, Amsterdam, Netherlands.

Wiesman, Z. and Lavee, S. (1995). Enhancement of IBA stimulatory effect on rooting of olive cultivar stem cuttings. Sci Hort. 62, 189-198. 